\title{
Study of container using hybrid technique for sulfuric acid decomposition of thermochemical water-splitting iodine-sulfur process
}

\author{
Ikuo IOKA*, Jin IWATSUKI*, Yoshiro KURIKI**, Daisuke KAWAI***, Hiroki YOKOTA***, \\ Shinji KUBO*, Yoshiyuki INAGAKI* and Nariaki SAKABA* \\ *Japan Atomic Energy Agency \\ 2-4 Shirakata, Tokai-mura, Ibaraki 319-1195, Japan \\ E-mail: ioka.ikuo@jaea.go.jp \\ **Japan Gasoline Company Corporation \\ 2-3-1 Minatomirai, Yokohama, Kanagawa 220-6001, Japan \\ ***TOCALO \\ 14-3 Minamifutami, Akashi, Hyogo 674-0093, Japan
}

Received: 16 July 2019; Revised: 10 November 2019; Accepted: 2 December 2019

\begin{abstract}
A thermochemical water-splitting iodine-sulfur process (IS process) is one of the candidates for the large-scale production of hydrogen using heat from solar power or nuclear energy. Severe corrosive environment which is thermal decomposition of sulfuric acid exists in the IS process. To achieve the IS process, one of the key factors is the development of structural materials against the severe corrosive environment. A hybrid material with the corrosion-resistance and the ductility was made by a silicon powder plasma spraying and laser treatment. The hybrid materials had excellent corrosion resistance in the condition of 95 mass $\%$ boiling sulfuric acid. This was attributed to the formation of $\mathrm{SiO}_{2}$ on the surface. To confirm the manufacturability of a container using the hybrid technique, the production of container with a welded part, a chamfer and a curved surface was experimentally tried. A configuration of the container is $150 \mathrm{~mm}$ inside diameter, $120 \mathrm{~mm}$ in height and $6 \mathrm{~mm}$ in thickness. In the production process of the container, the treatment of the welded part is very important. The preliminary examination of the welded part was carried out using Hastelloy C276 plates. The distance between fusion line and the plasma spraying and laser treatment area was decided to $15 \mathrm{~mm}$ from the results of the preliminary examination. The container firstly divided into the upper and the lower part, the inside of them was conducted the plasma spraying and laser treatment and then they were welded by a tungsten inert gas. Finally, the surface of the welded part was covered by plasma spraying and laser treatment. There was no detachment in the plasma spraying and laser treated layer of the container after the laser treatment. We succeeded in the production of the container using the hybrid technique.
\end{abstract}

Keywords : Plasma spraying, Laser treatment, Boiling sulfuric acid, Container, Welded part, Iodine-sulfur (IS) process

\section{Introduction}

Energy is central to achieve the interrelated economic, social, and environmental aims of sustainable human development. But if we are to realize this important goal, the kinds of energy we produce and the ways we use them will have to change. Otherwise, environmental damage will accelerate, inequities will increase, and global economic growth will be jeopardized. The need for renewable energy sources has been emphasized by the global environmental issues widely recognized recently. Hydrogen is very attractive for the future because it is renewable as an energy resource and it's also flexible as an energy carrier (Midilli et al., 2008). One of remarkable methods for large scale hydrogen production is water-splitting through thermochemical cycles. The iodine-sulfur process (IS process) is very promising and expected 
to utilize renewable energy or nuclear energy as a water-splitting process (Rosen, 2010; Brown et al., 2003; Onuki et al., 2009).

The IS process is composed of three processes, a Bunsen reaction, a thermal decomposition of hydrogen iodide and a thermal decomposition of sulfuric acid, as shown in Fig.1. By carrying out three reactions sequentially, as a net balance

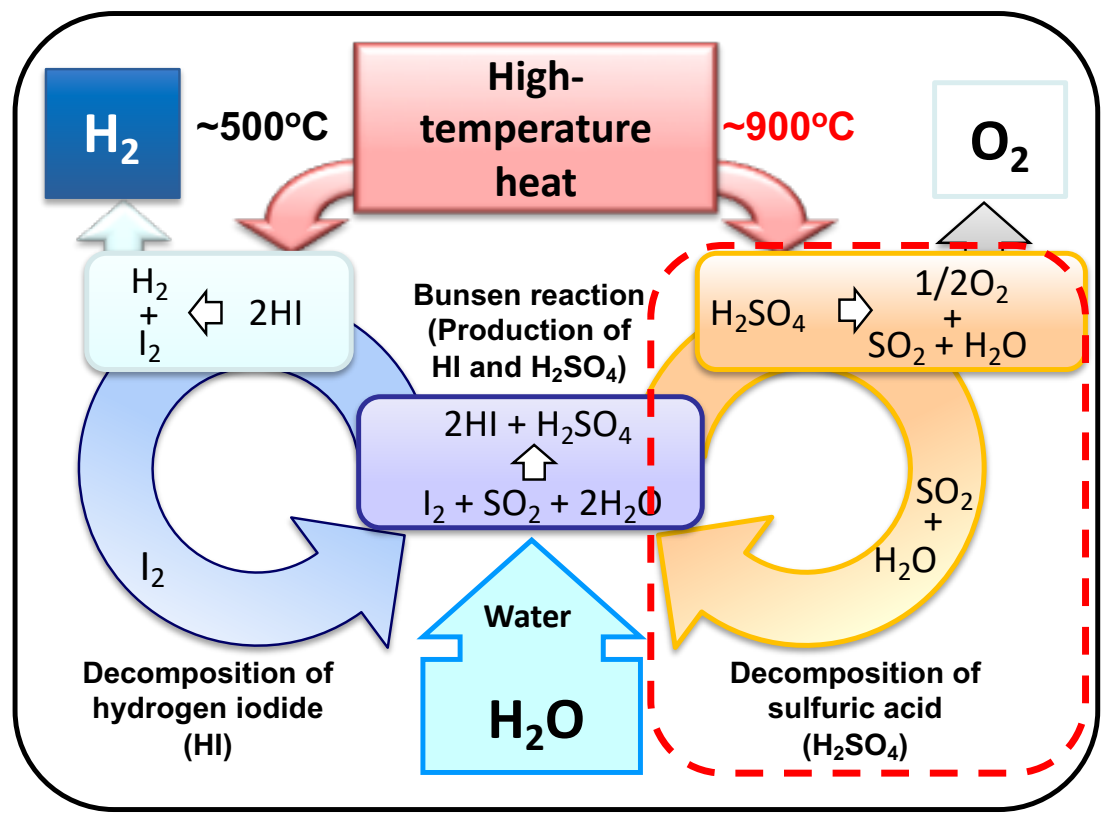

Fig.1 Schematic flow shows the IS process. The IS process is composed of the following three chemical reactions, the Bunsen reaction, thermal decomposition of hydrogen iodide and thermal decomposition of sulfuric acid. Each reaction temperature is $120^{\circ} \mathrm{C}, 400{ }^{\circ} \mathrm{C}, 850^{\circ} \mathrm{C}$. Blue arrow is iodine cycle. Yellow arrow is sulfur cycle. Iodine and sulfur circulate in the circle and don't consume during hydrogen production. So, the IS process do not produce harmful waste. The sulfuric acid decomposition cycle is most severe corrosive environment.

of the process, water can be decomposed into hydrogen and oxygen (Onuki et al., 1996). Sulfuric acid from the Bunsen reaction is purified and concentrated and then it is decomposed into $\mathrm{O}_{2}$ and $\mathrm{SO}_{2}$ finally. The severe thermal and highly oxidizing environment for the sulfuric acid decomposition (red dotted line) presents significant engineering challenges. Considering that the IS process is operated under very severe environments of iodic and sulfuric acids at a wide temperature range from room temperature to $850{ }^{\circ} \mathrm{C}$, material corrosion must be an important issue for accomplishment of the successful IS process. Therefore, candidate industrial materials have been screened from the viewpoint of corrosion resistance to the environments in the sulfuric acid decomposition process. Evaluation of materials for the sulfuric acid decomposition by immersion tests has revealed that high silicon alloys, silicon carbides and silicon nitrides have excellent corrosion resistance in 98 mass\% boiling sulfuric acid (Ioka et al., 1997). These materials are brittle, however, so it's difficult to use them independently as structural materials. So, a hybrid material that combined the corrosion-resistant and the pressure-resistant functions was made by a plasma spraying and laser treatment. The flat specimen of the hybrid material showed enough corrosion resistance in 95 mass\% boiling sulfuric acid though some cracks were observed in the surface layer from the cross-section observation (Ioka et al., 2015). Moreover, it is reported that the round bar specimen with a curvature had excellent corrosion resistance in the condition of 95 mass $\%$ boiling sulfuric acid to confirm the applicability of the hybrid material as the structural material (Ioka et al., 2016).

In the present work, a container with a welded part, a chamfer and curved surface was experimentally made by the plasma spraying and laser treatment to confirm the production characteristics of the component of IS process using the hybrid technique. Before the manufacture of the container, the preliminary examination of the welded part was carried out using plates of hybrid material. The evaluation of the container that paid attention to the welded part was performed using an optical microscope (OM), a scanning electron microscope (SEM) and a digital microscope (DM). 


\section{Experimental procedures}

The sulfuric acid decomposition apparatus for the IS process is comprised of a vessel, a pipe, a heat transfer tube, a flange, and so on. There components have a welding, a curved surface, chamfering. To confirm the production characteristics of the container using the hybrid material, the container which has a welded part, a chamfer, a curved surface was experimentally made.

\subsection{Materials}

Hastelloy C276 as the base metal was used in this work because it is known for its corrosion resistance in a wide range of aggressive media. The high molybdenum content imparts resistance to localized corrosion such as pitting. The low carbon minimizes carbide precipitation during welding to maintain resistance to intergranular attack in heat-affected zones of welded joints. It is used in chemical processing, pollution control, pulp and paper production, industrial waste treatment. In chemical processing, the alloy is used for components including heat exchangers, reaction vessels, evaporators and transfer piping. The chemical compositions of Hastelloy C276 are shown in Table 1. A round bar for the container, the plates for the preliminary welding examination were prepared.

Table 1 Chemical compositions of Hastelloy C276 (mass\%). It had a good corrosion resistance relatively in the alloys.

\begin{tabular}{cccccccccc}
$\mathrm{Ni}$ & $\mathrm{Cr}$ & $\mathrm{Mo}$ & $\mathrm{W}$ & $\mathrm{Fe}$ & $\mathrm{C}$ & $\mathrm{Si}$ & $\mathrm{Mn}$ & $\mathrm{P}$ & $\mathrm{S}$ \\
\hline 57.51 & 16.0 & 16.1 & 3.6 & 5.9 & 0.005 & 0.03 & 0.32 & 0.004 & $<0.002$
\end{tabular}

The hybrid material was made by a silicon powder plasma spraying and laser treatment. Before the plasma spraying and laser treatment, the surface of the base material was sand blasted using alumina grit with the size in the range from 125 to $250 \mu \mathrm{m}$. Argon was used as a carrier gas. Si powder with the size in $10 \mu \mathrm{m}$ was deposited onto the surface by air plasma spraying. Figure 2 shows the cross section of the Si plasma sprayed specimen. The thickness of Si layer was about $100 \mu \mathrm{m}$. The Si layer adhered with a base metal well physically. Many pores were observed in the Si layer. The deposited Si layer was treated by a laser, a pulsed YAG laser $(\phi 200 \mu \mathrm{m})$, in order to improve the performance of the plasma sprayed layer, such as its adhesion to the substrate, reduction of pores in the layer, and to modified the chemical composition of the plasma sprayed layer. The hybrid material was made repeating the above-mentioned processing twice.

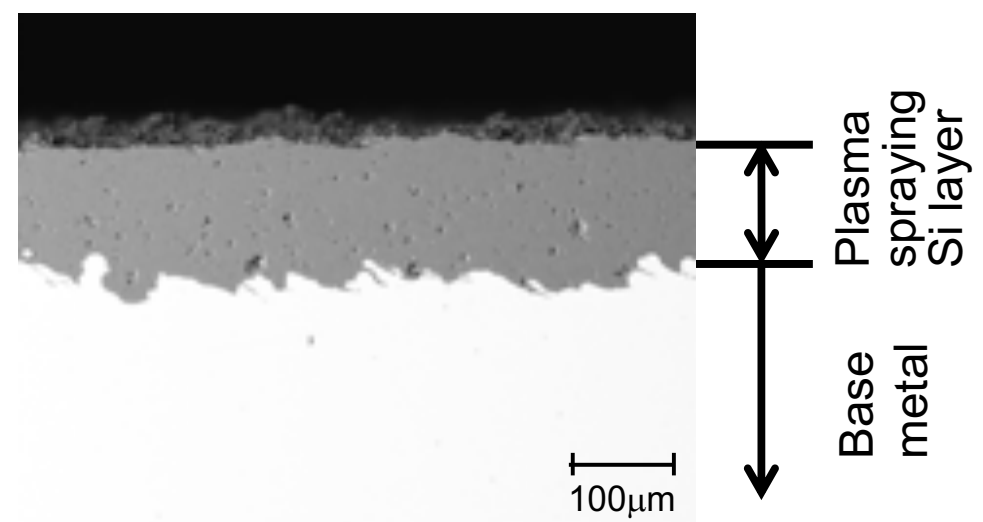

Fig. 2 Cross section of the Si plasma sprayed specimen on the base metal. The Si layer adhered with the base metal well physically and included many pores of around dozens of microns in diameter.

\subsection{Preliminary welding examination}

In the production process of the container using the hybrid technique, the treatment of the welded part is very important. It is necessary to decide the distance between a fusion line and the plasma spraying and laser treatment area so that the weld process does not have an influence on the plasma spraying and laser treatment area. The purpose of the examination is to decide the distance between the fusion line and the plasma spraying and laser treatment area. The preliminary welding examination was carried out using Hastelloy C276 plates of the hybrid material. Figure 3 shows a 
making procedure of the welding specimen. Dimensions of the plates were $150 \mathrm{~mm}$ in height, $100 \mathrm{~mm}$ in width and $6 \mathrm{~mm}$ in thickness. The shape of the welded part was single $U$ groove. The chemical compositions of filler wire are shown in Table 2. The compositions of the filler wire are same as the base metal mostly. The plasma spraying and laser treatment were conducted on the surface of the Hastelloy C276 plates as shown in Fig.4. The distance between the center of the single $U$ groove and the plasma spraying and laser treatment area were $5 \mathrm{~mm}, 10 \mathrm{~mm}, 15 \mathrm{~mm}$ and 20 mm, respectively.

Two plates were welded by a tungsten inert gas (TIG) with Hastelloy C276 filler wire, using a current of 90-110 $\mathrm{A}(\mathrm{DC})$ and a voltage of 19-21 V. The welding speed were around $7 \mathrm{~mm} / \mathrm{min}$. Four-passes of TIG welding was carried out along the single $U$ groove to produce the welded part. The process parameters employed for the TIG welding is shown in Table 3. The current and the voltage were changed at each pass.

Moreover, the plasma spraying and laser treatment was given to the part of the welded part. The samples for cross section observation were cut transversely to the welded part and polished using standard metallographic techniques. To confirm the influence of the TIG welding on the plasma spraying and laser treatment layer, the layer of the welded part was compared with that of the base metal part.

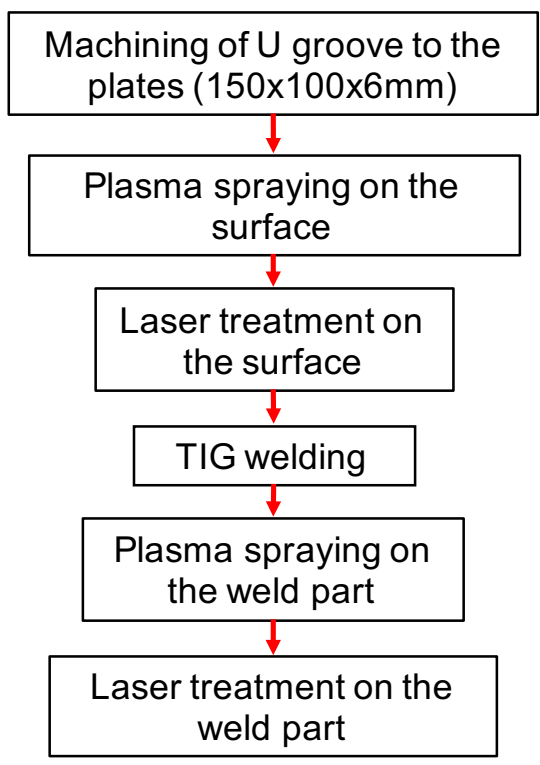

Fig.3 Making procedure of the welding specimen. A single U groove was machined in one end of Hastelloy plate. Dimensions of the plates were $150 \mathrm{~mm}$ in height, $100 \mathrm{~mm}$ in width and $6 \mathrm{~mm}$ in thickness.

Table 2 Chemical compositions of the filler wire (mass\%). The compositions of the filler wire are same as the base metal mostly.

\begin{tabular}{cccccccccc}
$\mathrm{Ni}$ & $\mathrm{Cr}$ & $\mathrm{Mo}$ & $\mathrm{W}$ & $\mathrm{Fe}$ & $\mathrm{C}$ & $\mathrm{Si}$ & $\mathrm{Mn}$ & $\mathrm{P}$ & $\mathrm{S}$ \\
\hline 57.09 & 15.9 & 16.0 & 3.4 & 5.4 & 0.002 & 0.01 & 0.50 & 0.005 & 0.006
\end{tabular}

Table 3 Welding conditions for the TIG welding. The current and the voltage were changed at each pass.

\begin{tabular}{cccc} 
Current & Voltage & Welding speed & Welding pass \\
\hline $90-110 \mathrm{~A}(\mathrm{DC})$ & $19-21 \mathrm{~V}$ & $7 \mathrm{~mm} / \mathrm{min}$ & 4 passes
\end{tabular}




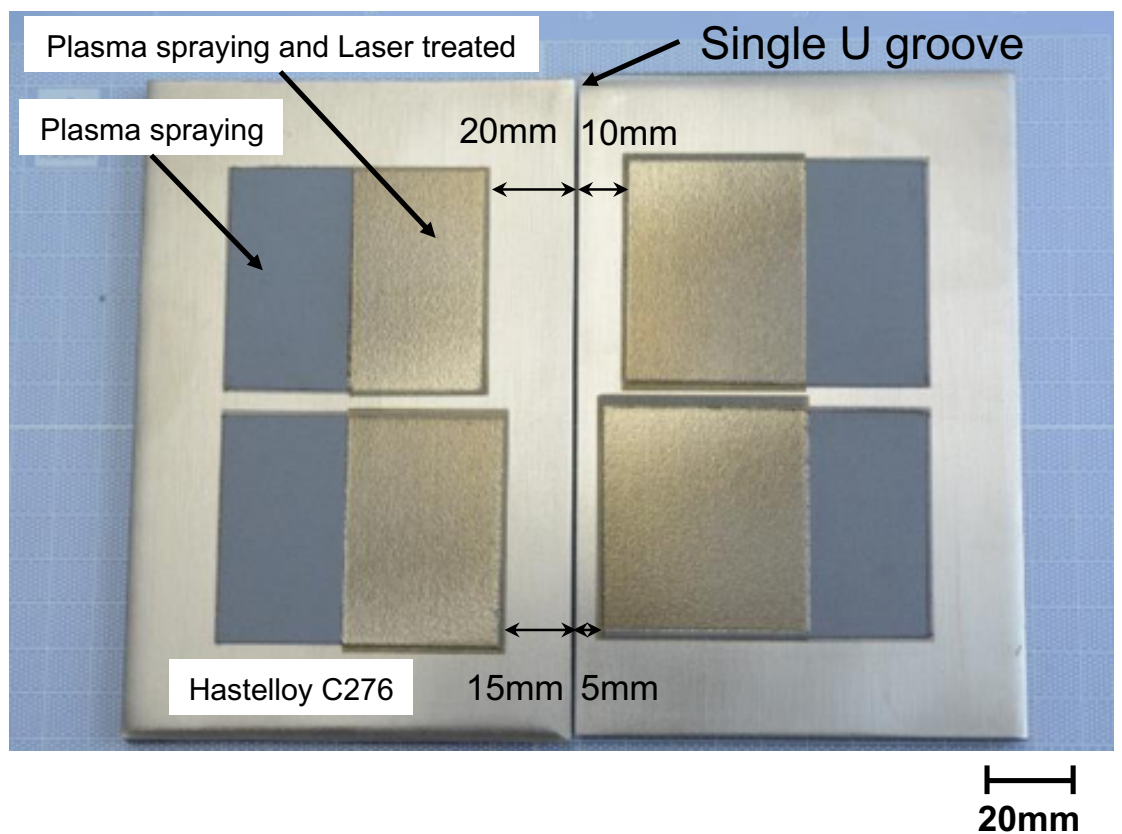

Fig.4 Appearance of Hastelloy C276 plates with the plasma spraying and laser treatment before TIG welding. The plasma spraying and laser treatment (yellow color) were conducted on the surface of the plates.

\subsection{Production of the container}

To confirm the production characteristics of the container using the hybrid technique, the container was experimentally made. The container has a welded part, a chamfer, a curved surface, an R processing and a sealing surface. The $\mathrm{R}$ processing is carried out between the inner curved surface and the inner bottom of the container. These parts are required to fabricate the components of the IS process plant, such as a reaction vessel, a pipe, a flange and so on. The container consists of an upper part and a lower part as shown in Fig.5. A size of the container is about $150 \mathrm{~mm}$ inside

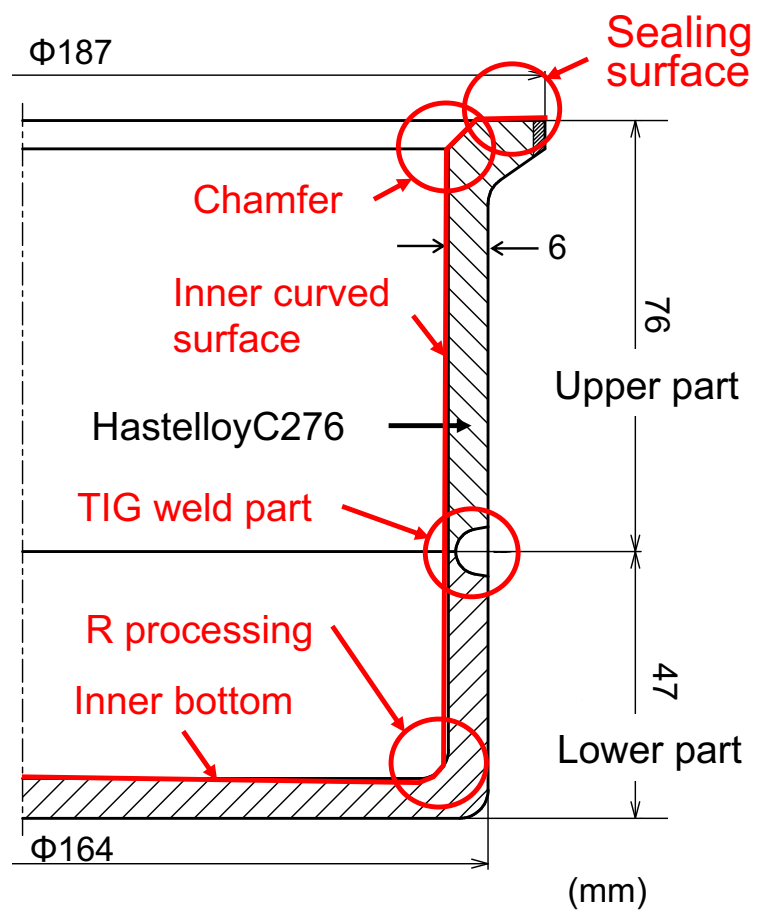

Fig.5 Configuration of the container made of Hastelloy C276. Red circles and red line are required to fabricate the components of the IS process plant. 
diameter, $120 \mathrm{~mm}$ in height and $6 \mathrm{~mm}$ in thickness. The container is made of Hastelloy C276.

The plasma spraying and laser treatment was performed the inside of the upper and the lower parts except for the neighborhood of the weld place. The upper and the lower parts were welded by TIG. Finally, the whole welded part was covered by the plasma spraying and the laser treatment. The inside of the container was observed using the DM in order to check the morphology of the surface.

\section{Results and discussion}

\subsection{Corrosion property of the specimen using hybrid technique}

Mechanism of corrosion resistance of the hybrid specimen is described in this section. Figure 6 shows the surface and the cross section of the specimen using hybrid technique. The surface of the sample had a wavy irregularity of around $200 \mu \mathrm{m}$ in width as shown in Fig.6(a). The wavy irregularity on the surface was formed by the laser treatment. The surface roughness was approximately $20 \mu \mathrm{m}$. Some thin cracks were also observed on the surface. Fig. 6(b) shows the cross section of the vicinity of the surface. It was confirmed that the plasma spraying and laser treated layer became 2 laminar structure. Some cracks stopped in the plasma spraying and laser treatment layer, but some cracks progressed to the base metal from the cross-sectional observation. The plasma spraying Si layer and the base metal under the layer was melted by the laser in order to improve the performance of the plasma sprayed layer. So, it is considered that these cracks are the solidification breaking. The plasma spraying and laser treatment layer may not be effective in corrosion resistance of the specimen, since several cracks existed in the layer. The corrosion test of the specimen using hybrid technique was tried in a boiling sulfuric acid.
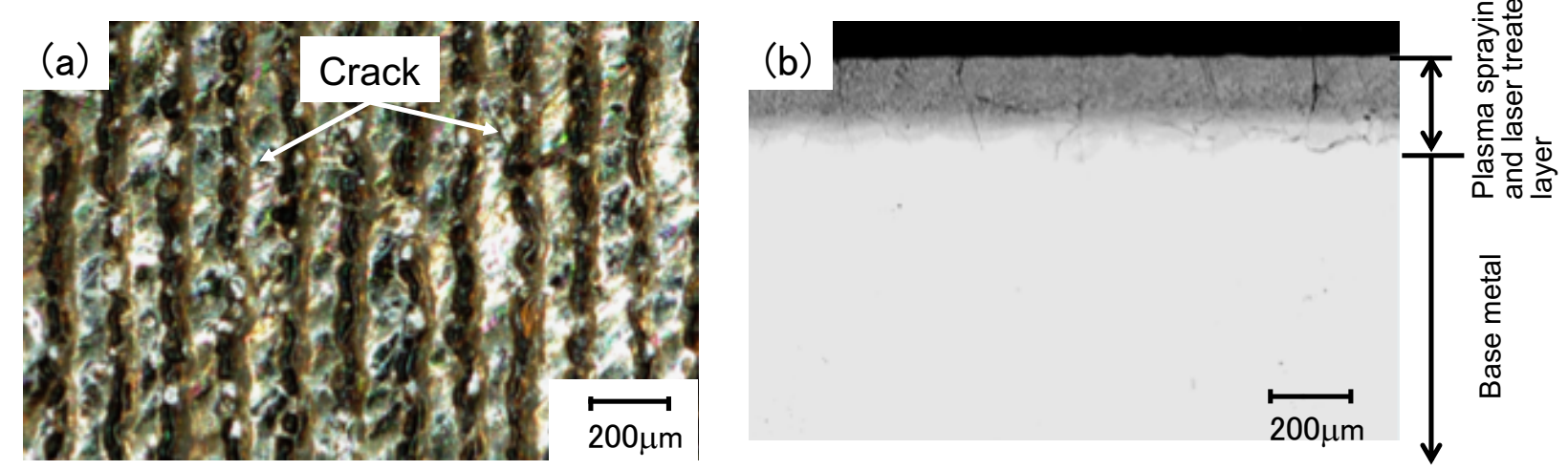

Fig.6 Micrographs of the specimen using hybrid technique (a) surface and (b) cross section. The wavy irregularity on the surface was formed by the laser treatment. Many thin cracks were observed on the surface and in the cross section.

Corrosion tests were performed in 95 mass \% boiling sulfuric acid at $300{ }^{\circ} \mathrm{C}$ until 300 hours by the specimen using hybrid technique. The test period was defined as the time between the moment when the boiling began and the moment when the heater was shut off. The weight of the specimens before and after the corrosion test was measured using an electric balance to calculate the corrosion rate. There was no detaching of the plasma spraying and laser treatment layer after the corrosion test. Figure 7 shows the corrosion rate in 95 mass $\%$ boiling sulfuric acid as a function of immersion time. The corrosion rate in 95 mass \% boiling sulfuric acid decreased with increase in immersion time. The corrosion rate in $95 \mathrm{mass} \%$ boiling sulfuric acid for 300 hours was about $0.01 \mathrm{~mm} / \mathrm{y}$. The cross section of the specimen after the corrosion test was analyzed using the SEM/EDX in order to investigate the superior corrosion resistance of the specimen. Figure 8 illustrates backscattered electron (BSE), O, Si, Cr, Fe, Ni and Mo images in the vicinity of the surface. All elements were uniformly distributed in each layer. The chemical compositions of upper and lower plasma spraying and laser treated layers were 53 mass $\%(\mathrm{Si}), 24$ mass\%(Ni), 7 mass $\%(\mathrm{Cr}), 8$ mass $\%(\mathrm{Mo}), 3$ mass $\%(\mathrm{Fe}), 4 \mathrm{mass} \%(\mathrm{~W})$ and 27 mass $\%(\mathrm{Si}), 34$ mass\%(Ni), 16 mass\%(Cr), 14 mass\%(Mo), 6 mass\%(Fe), 3 mass\%(W), respectively. The Si contents of the upper layer is higher than that of the lower layer. The both layers included enough Si contents (more than 14 mass\%, (Ioka et al., 1997)) against corrosion of boiling sulfuric acid. So, it is believed that silica $\left(\mathrm{SiO}_{2}\right)$ was formed on the surface and the gap of cracks since $\mathrm{O}$ and $\mathrm{Si}$ were observed on the surface and in the cracks as shown in Fig.8. Thus, cracks in 
the plasma spraying and laser treatment layer were sealed by the formation of $\mathrm{SiO}_{2}$ under the boiling sulfuric acid (severe thermal and highly oxidizing environment). It is thought that the superior corrosion resistance of the specimen using hybrid technique was accomplished by the formation of $\mathrm{SiO}_{2}$.

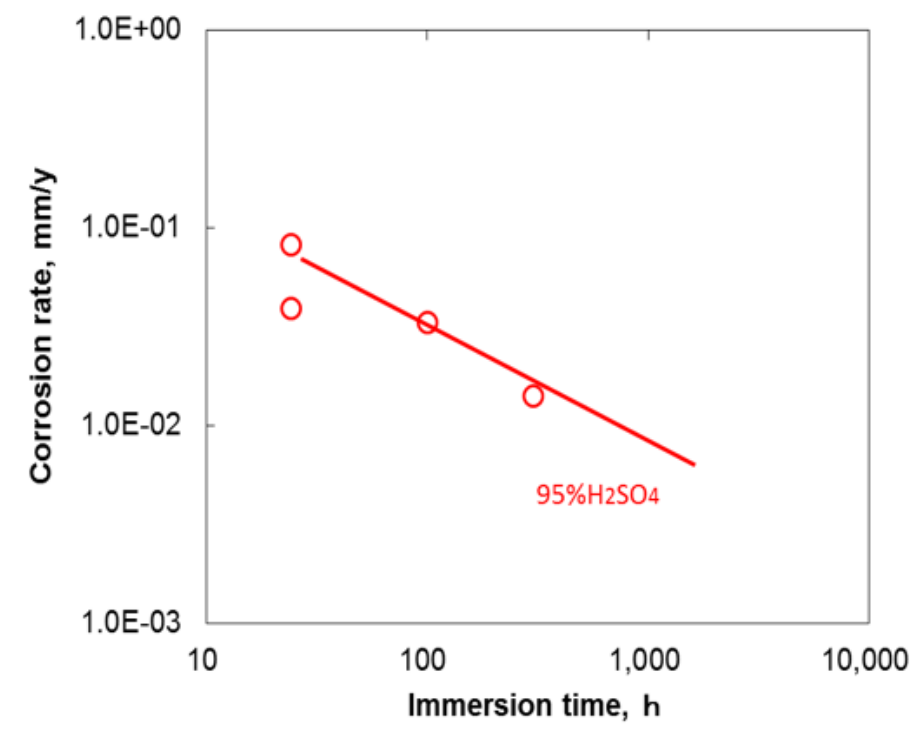

Fig.7 Relationship between the corrosion rate and immersion time of 95 mass $\%$ boiling sulfuric acid. Corrosion rate in 95 mass\% boiling sulfuric acid for 300 hours was about $0.01 \mathrm{~mm} / \mathrm{y}$.
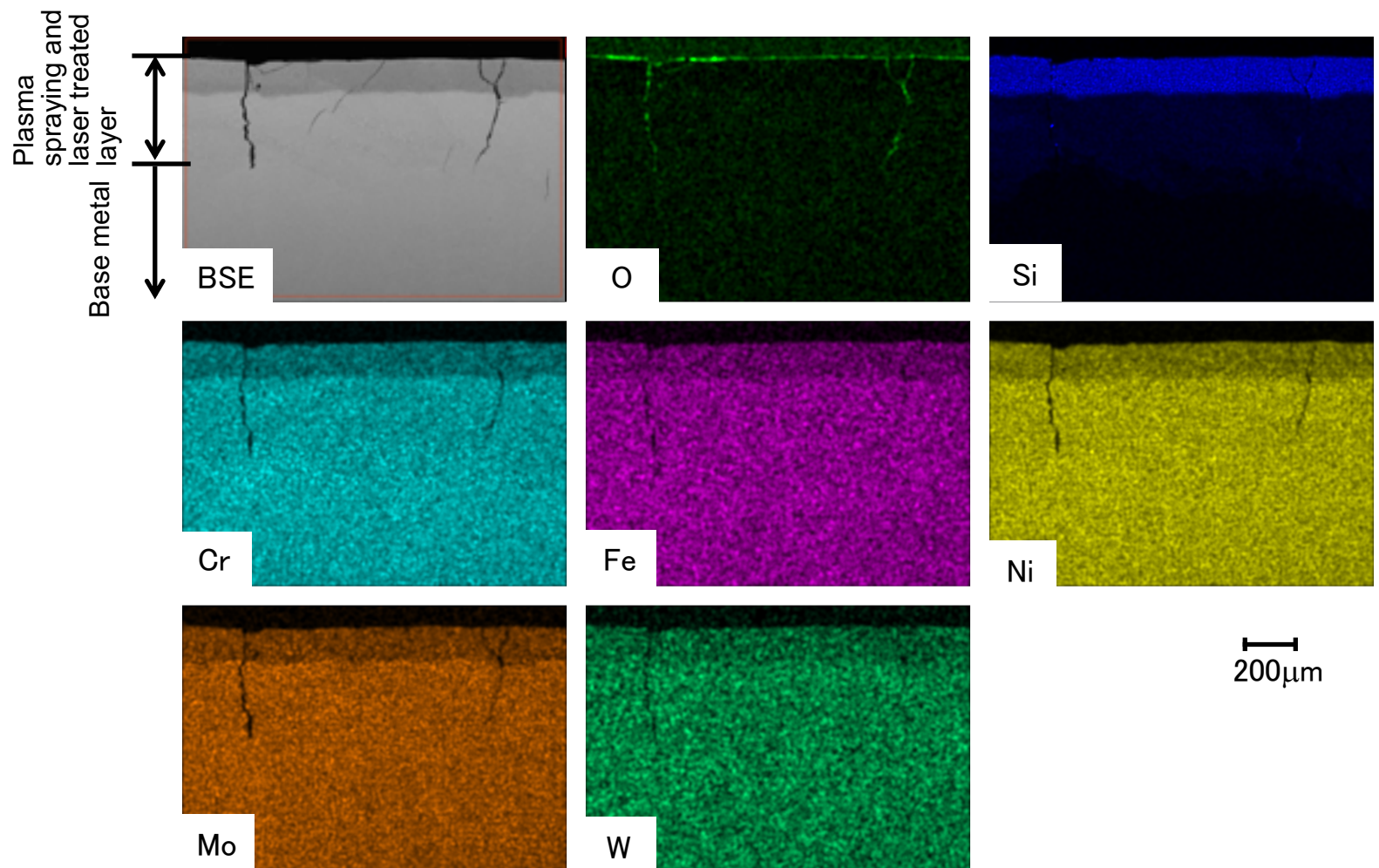

Fig. 8 Area analysis of the cross section of the specimen after the corrosion test for $300 \mathrm{~h}$. All elements were uniformly distributed in the upper and lower plasma spraying and laser treated layers. Concentration of $\mathrm{O}$ and $\mathrm{Si}$ were observed on the surface and in the cracks. 


\subsection{Preliminary welding examination}

An appearance of the plate welded by TIG is shown in Fig.9. The surface of the weld bead was improved mechanically. A temper color was observed around the weld bead as shown in Fig.9(a). There is a space between the temper color and the edge of the plasma spraying and laser treatment in the case of $15 \mathrm{~mm}$ and $20 \mathrm{~mm}$ from the fusion line. So, it is expected that the temperature of the edge of the plasma spraying and laser treatment was less than $450{ }^{\circ} \mathrm{C}$ in the case of $15 \mathrm{~mm}$ and $20 \mathrm{~mm}$. Figure 9(b) shows the magnification of the plasma spraying and laser treated layer at the red circle in Fig.9(a). It seems that there was no influence of TIG welding on the plasma spraying and laser treated layer on the base metal. Figure 9(c) shows the cross section at the red circle in Fig.9(a). There is few chips of the plasma spraying and

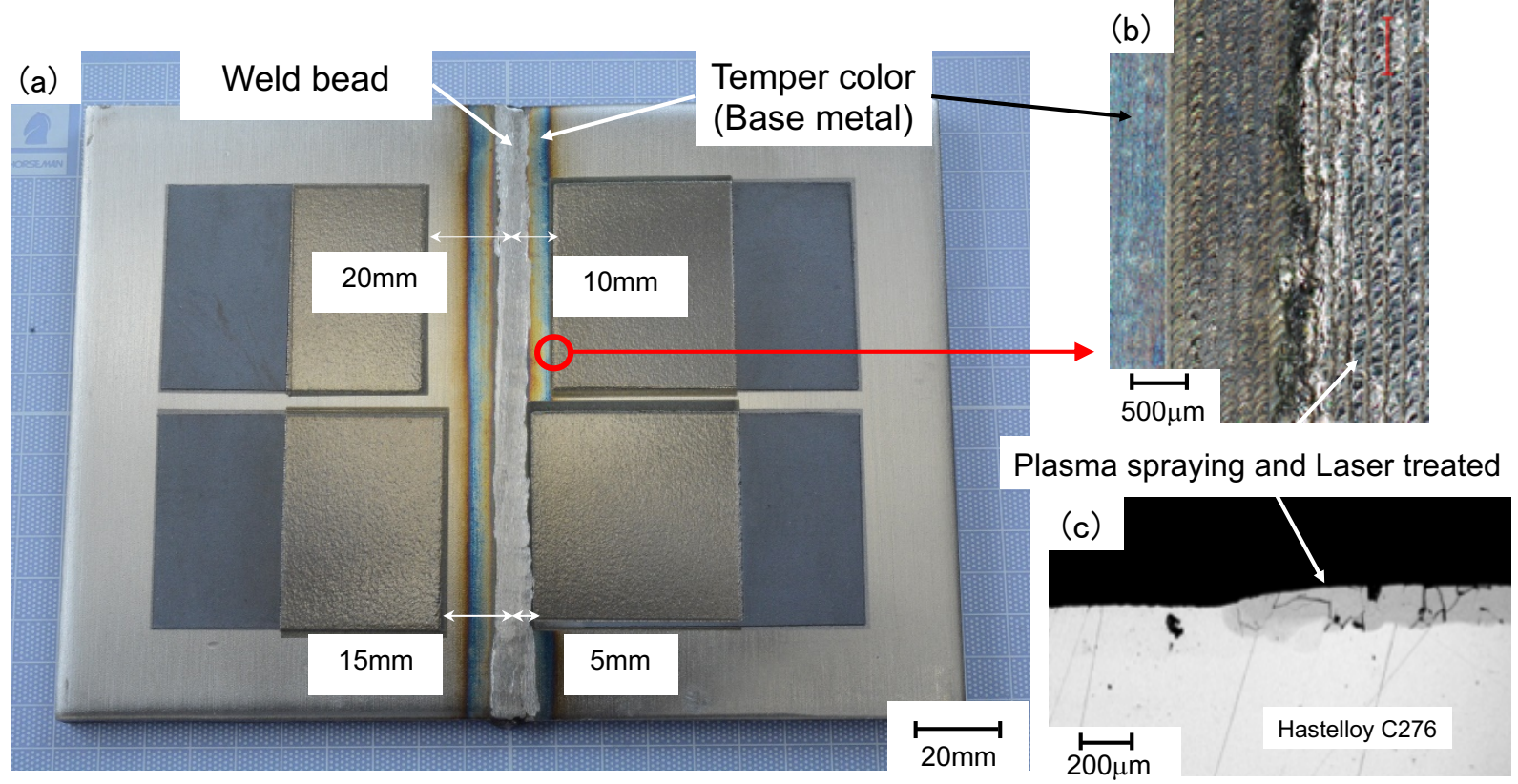

Fig.9 Plate specimen for the preliminary welding examination (a)appearance of the plate welded by TIG, (b)surface and (c)cross-section at the red circle. Few chips of the plasma spraying and laser treated layer were observed in the cross section.

laser treated layer after the TIG welding. It seems that some detachment in Fig.9(c) occurred at the time of the cutting or the polishing of the specimen. It is believed that there was no influence of TIG welding on the plasma spraying and laser treated layer.

Figure 10 shows an appearance of the plate specimen after the plasma spraying and the laser treatment on the welded part. The surface of the plasma spraying and laser treated layer on the weld metal is shown in Fig. 10(b). The wavy irregularity and some thin cracks were also observed on the surface like Fig.6(a). The detachment was not observed in the plasma spraying and laser treated layer on the welded part and temper color part. The layer adhered tightly in all distance between the fusion line and the plasma spraying and laser treatment area. Figure 10(c) shows cross section at the red circle in Fig.10(a). There is no detachment between the plasma spraying and laser treated layer and the weld metal. Figures $10(\mathrm{~d})$ and 10(e) show the magnification of the plasma spraying and laser treated layer on the weld metal and the base metal. The aspect of the plasma spraying and laser treated layer is same as that of Fig.6(b) mostly. It seems that the adhesion between the plasma spraying and laser treated layer and the weld metal with dendrite structure is good. There is little difference in the state of the plasma spraying and laser treated layer of the base metal and the weld metal. Many cracks were observed in the plasma spraying and laser treatment layer on the weld metal and the base metal. Some cracks progressed to the base metal. However, it is expected these cracks in the plasma spraying and laser treatment layer were sealed by the formation of $\mathrm{SiO}_{2}$ under the boiling sulfuric acid.

So, the distance between the fusion line and the plasma spraying and laser treatment area was decided to $15 \mathrm{~mm}$ from the results of cross-sectional observation and the appearance inspection (especially temper color area). 


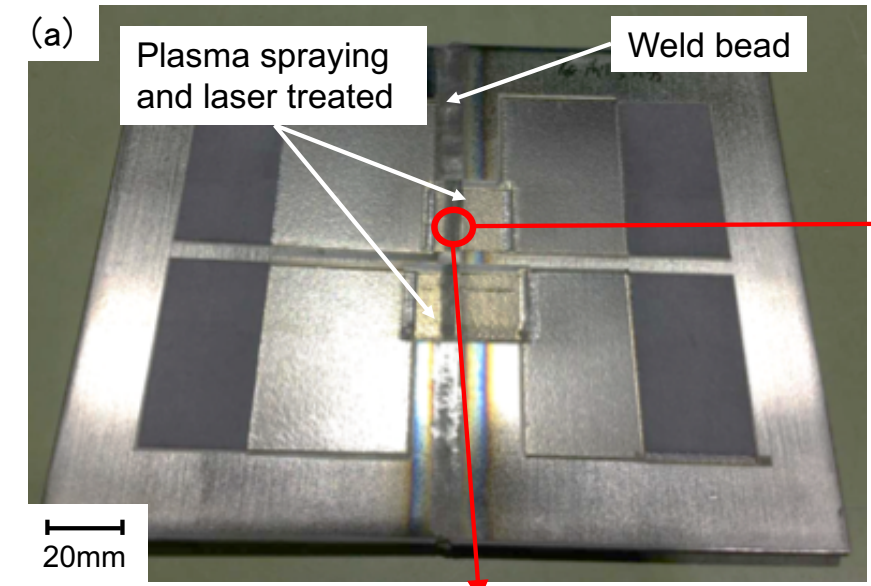

(c)
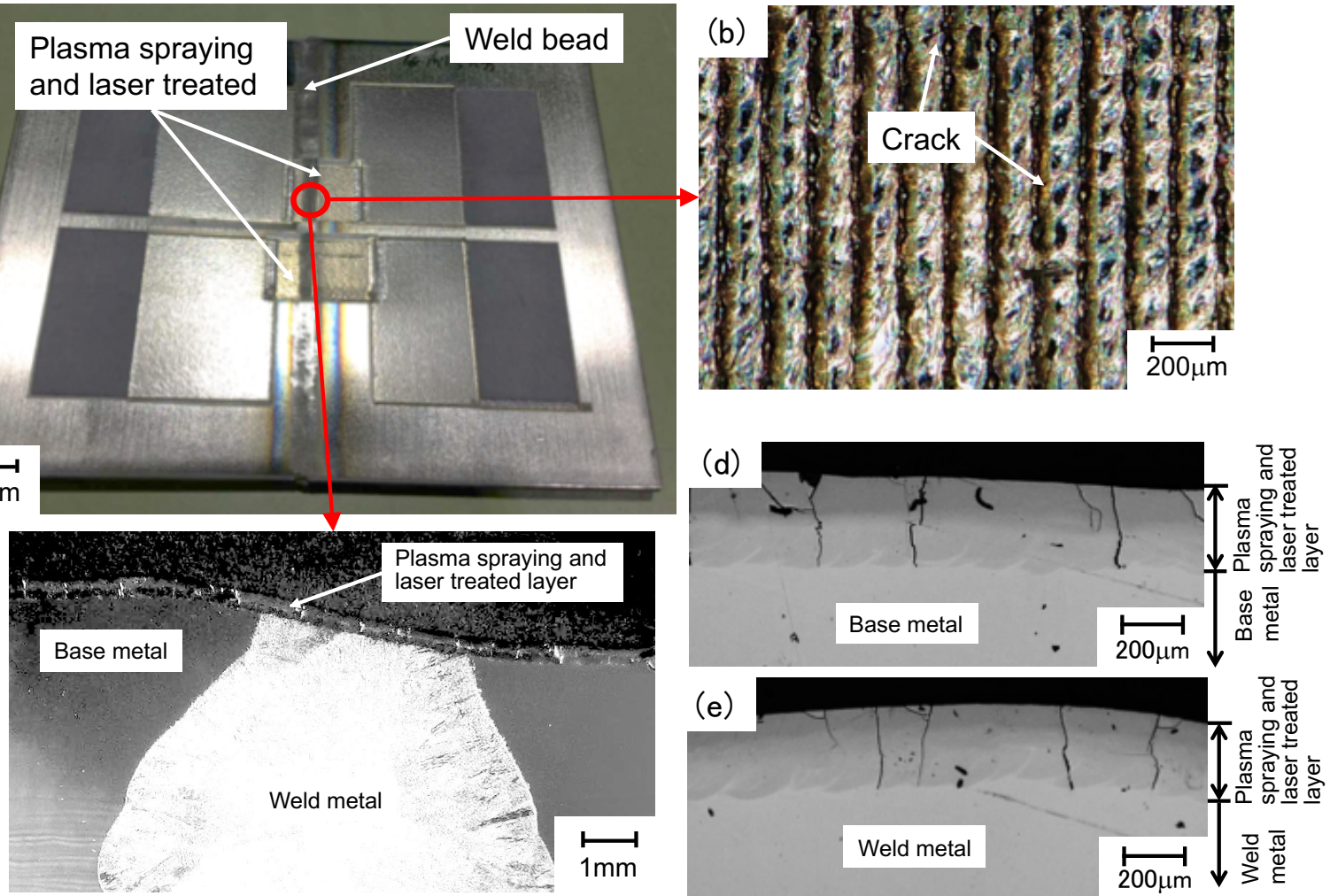

Fig.10 Plate specimen for the preliminary welding examination (a)appearance of the plate specimen after the plasma spraying and the laser treatment on the welded part, (b)surface and (c)cross-section at the red circle, (d) magnification of the plasma spraying and laser treated layer on the base metal, (e) magnification of the plasma spraying and laser treated layer on the weld metal. The detachment was not observed in the plasma spraying and laser treated layer on the welded part.

\subsection{Production of the container}

A photo of the inner part of the container using the hybrid technique is shown in Fig.11. The center of the bottom

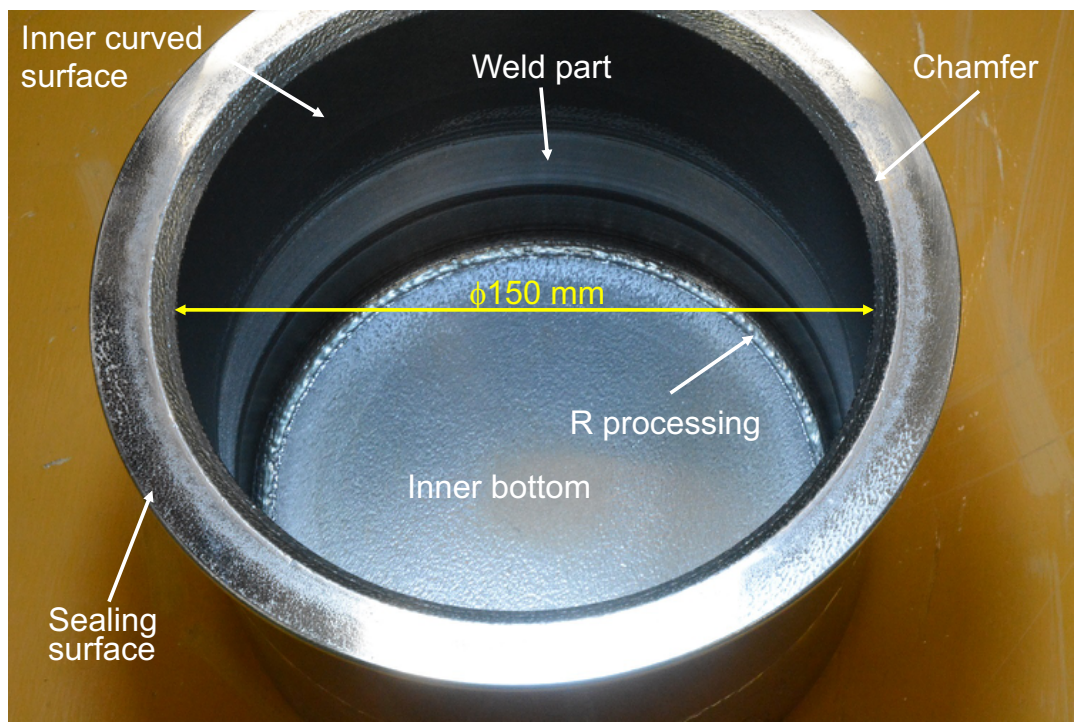

Fig.11 Appearance of the inner part of the container. The welded part, the chamfer, the curved surface, the R processing and the sealing surface were covered by the plasma spraying and laser treated layer. 
looks stronger in a metal color than the circumference. The surface of the bottom was homogeneous by the visual observation. It seems that the difference in vanity of the bottom is attributed to the wavy irregularity of the surface and the undulation of the light. The surface condition of the inner part of the container was also observed by a digital microscope. The container manufactured by the plasma spraying and the laser treatment did not have the distortion and the detachment of the plasma spraying and laser treated layer at the welded part, the chamfer, the curved surface, the $\mathrm{R}$ processing and the sealing surface.

Figure 12 shows the detail appearance of the container with the plasma spraying and laser treated inner layer at each part, such as sealing surface, chamfer, R processing, inner curved surface and inner bottom. There is no detachment of the plasma spraying and laser treated layer on the inner part, though there are some differences of surface morphology. Only the sealing surface was mechanically polished by emery paper of \#1200 after the plasma spray and laser treatment to get good contact with O-ring.

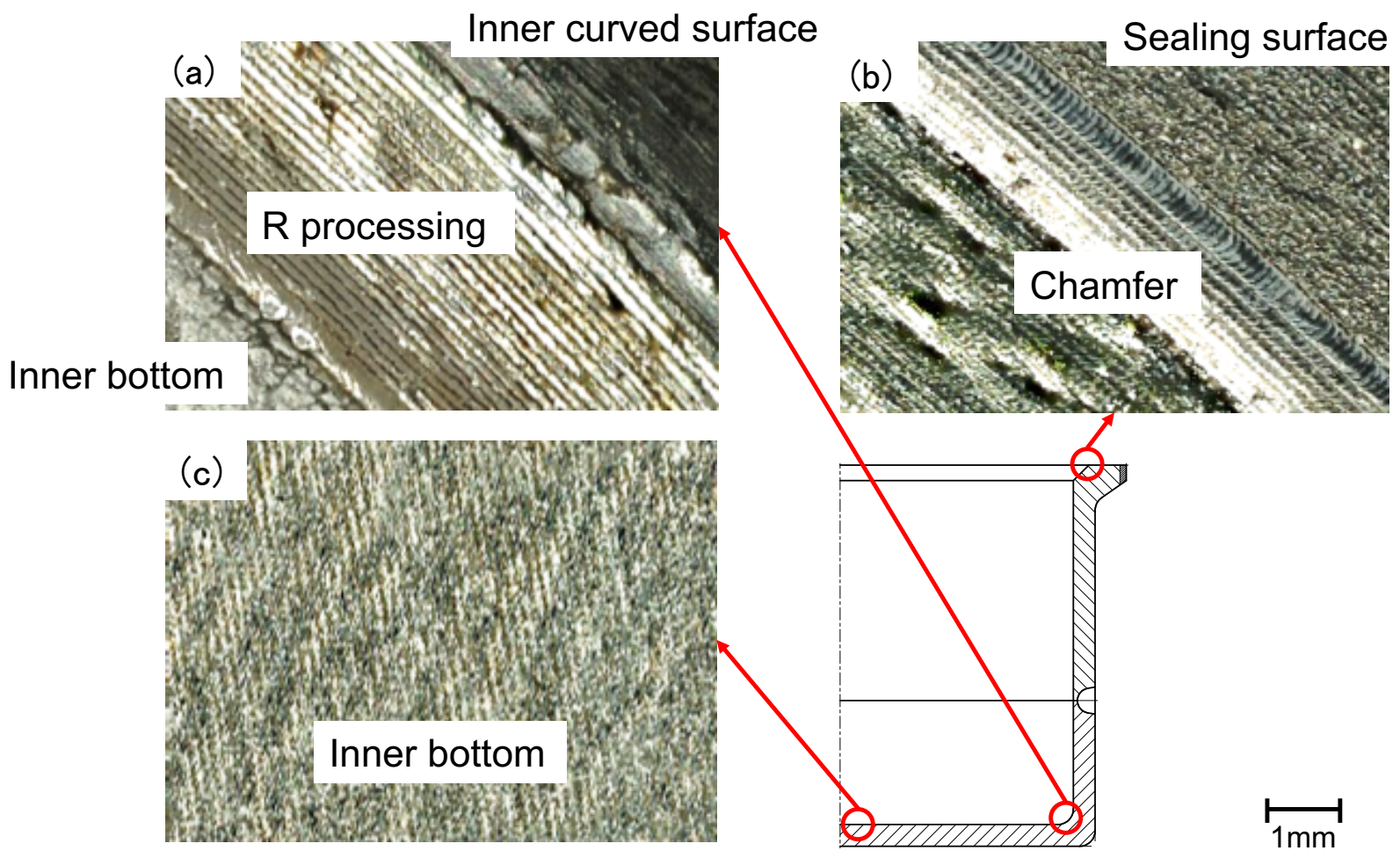

Fig.12 Each part of the hybrid container with the plasma spraying and laser treated inner layer (a) R processing and inner curved surface, (b) sealing surface and chamfer, (c) inner bottom. The wavy irregularity on the surface of all plasma spraying and laser treated inner layers was observed.

\section{Conclusions}

The hybrid container with the welded part, the sealing surface, the chamfer, the R processing, the inner curved surface and the inner bottom was made by a silicon powder plasma spraying and laser treatment. There is no detachment of the plasma spraying and laser treated layer on the base metal and the welded part. We succeeded in the production of the container using the hybrid technique.

In future, a boiling sulfuric acid test using the container will be performed to evaluate the corrosion characteristic of the container.

\section{Acknowledgments}

This work was supported by Council for Science, Technology and Innovation (CSTI), Cross-ministerial Strategic Innovation Promotion Program (SIP), "Energy Carrier” (Funding agency : JST). 


\section{References}

Brown, L.C., Besenbruch, G.E., Lentsch, G.E., Schltz, K.R., Funk, J.F., Pickard, P.S., Marshall, A.C. and Showlter, S.K., High efficiency generation of hydrogen fuels using nuclear power(2003), GA-A24285.

Ioka, I., Onuki, K., Futakawa, M., Kuriki, Y., Nagoshi, M., Nakajima, H. and Shimizu, S., Corrosion resistance of Fe-Si alloys in boiling sulfuric acid, Journal of the Society of Materials Science of Japan, Vol.46(1997), pp.1041-1045. (in Japanese)

Ioka, I., Kuriki, Y., Iwatsuki, J., Kubo, S. and Inagaki, Y., Development of hybrid material using plasma spraying and laser treatment for thermochemical water-splitting iodine-sulfur process, 6th World Hydrogen Tech. Conf. (WHTC2015) (2015), pp.65-66 (2015).

Ioka, I., Kuriki, Y., Iwatsuki, J., Kubo, S., Inagaki, Y. and Sakaba, N., Corrosion resistance of plasma spraying and laser treated material with curvature for thermochemical water-splitting iodine-sulfur process, 5th Asian Conf. on Innovative Energy and Environment Chemical Engineering (ASCON-IEEChE 2016) (2016), Poster064.

Midilli, A. and Dincer, I., Hydrogen as a renewable and sustainable solution in reducing global fossil fuel consumption, International Journal of Hydrogen Energy, Vol.33(2008), pp.4209-4222.

Onuki, K., Kubo, S., Terada, A., Sakaba, N. and Hino, R., Thermochemical water-splitting cycle using iodine and sulfur, Energy Environment Science, Vol.2(2009), pp.491-497.

Onuki, K., Nakajima, H., Ioka, I., Futakawa, M. and Shimizu, S., IS process for thermochemical hydrogen production (1996), JAERI-Review 94-006.

Rosen, M., Advances in hydrogen production by thermochemical water decomposition: a review, Energy, Vol.35(2010), pp.1068-1076. 